\title{
Off-label use of transmucosal ketamine as a rapid- acting antidepressant: a retrospective chart review
}

\author{
This article was published in the following Dove Press journal: \\ Neuropsychiatric Disease and Treatment \\ 14 October 2015 \\ Number of times this article has been viewed
}

\author{
Linda Nguyen ${ }^{1,2}$ \\ Patrick J Marshalek ${ }^{2}$ \\ Cory B Weaver' \\ Kathy J Cramer ${ }^{2,3}$ \\ Scott E Pollard ${ }^{2,4}$ \\ Rae R Matsumoto1,2,5 \\ 'Department of Pharmaceutical \\ Sciences, School of Pharmacy, West \\ Virginia University, Morgantown, \\ WV, USA; ${ }^{2}$ Department of Behavioral \\ Medicine and Psychiatry, School \\ of Medicine, West Virginia University, \\ Morgantown, WV, USA; ${ }^{3}$ Doctor of \\ Nursing Practice Program, Robert \\ Morris University, Moon Township, \\ PA, USA; ${ }^{4}$ Department of Behavioral \\ Health, West Park Hospital, Cody, \\ WY, USA; ${ }^{5}$ College of Pharmacy, Touro \\ University California, Vallejo, CA, USA
}

Correspondence: Rae R Matsumoto College of Pharmacy, Touro University California, I 10 Club Drive, Vallejo, CA 94592, USA

$\mathrm{Tel}+\mathrm{I} 7076385926$

Fax +I 7076385959

Email rae.matsumoto@tu.edu
Objective: This study evaluated the effectiveness and safety of subanesthetic doses of ketamine using an off-label, transmucosal administration route in patients with treatment-resistant depression.

Methods: A retrospective chart review was conducted to identify patients who met the inclusion criteria for treatment-resistant major depressive disorder. Seventeen such patients who received subanesthetic doses of ketamine were included. Patient demographics, efficacy (drug refill, clinician notes), side effects, and concurrent medications were assessed.

Results: Benefit from low-dose transmucosal ketamine was noted in $76 \%$ of subjects (average age 48 years, $88 \%$ female), with a dose duration lasting 7-14 days. No notable side effects were noted. The most common classes of concurrent medications to which ketamine was added were serotonin-norepinephrine reuptake inhibitors (59\%), stimulants (47\%), folate replacement (47\%), and benzodiazepines (47\%).

Conclusion: Our results provide preliminary evidence of the effectiveness and safety of lowdose transmucosal ketamine in treatment-resistant patients. A controlled, prospective pilot study is warranted to validate these findings.

Keywords: ketamine, depression, treatment resistance, NMDA receptor, glutamate, mood disorder

\section{Introduction}

Major depressive disorder (MDD) is a leading cause of disability worldwide, affecting an estimated 350 million people. ${ }^{1}$ Current limitations of pharmaceutical treatments include a delay in therapeutic efficacy of several weeks to months and a lack of efficacy in approximately a third of the patients with MDD, ${ }^{2,3}$ Revolutionizing the therapeutic armamentarium for the treatment of depression, the $N$-methyl-D-aspartate (NMDA) receptor antagonist ketamine administered at subanesthetic doses via an intravenous (iv) route can elicit robust, rapid, and sustained antidepressant effects, even in treatmentresistant patients. ${ }^{4-13}$ However, the need for iv administration limits the use of ketamine to an inpatient setting, requiring support services and monitoring..$^{14,15}$

To minimize the adverse events associated with iv ketamine, including acute dissociative and psychotomimetic effects and cardiovascular changes, ${ }^{7,14-16}$ recent investigations have attempted alternative routes of administration to elicit rapid antidepressant effects. ${ }^{17-28}$ Oral administration is the simplest route to implement. However, due to its lower bioavailability compared to iv administration, oral ketamine often requires higher or more frequent dosing. ${ }^{17-19,24,27}$ Intramuscular and intranasal administration of ketamine have yielded more promising results with improvement in depression measures in patients with MDD..$^{20,22}$ However, injectables are not a preferred administration route for many patients, ${ }^{28}$ and concerns surrounding inhaler use with regard to ease of reliable dosing and abuse potential remain. ${ }^{29}$ 
A transmucosal route of administration, in which a small amount of liquid ketamine (approximately $1 \mathrm{~mL}$ ) is absorbed through the oral mucosa rather than swallowed and thus increases bioavailability (17\% oral vs 30\% sublingual/ transbuccal), ${ }^{30}$ may prove more effective. We report herein a retrospective chart review of 17 patients with treatmentresistant MDD at a psychiatric clinic in Morgantown, WV, USA who received low-dose ketamine using this alternative route of administration, which is amenable to outpatient use. We examined the effectiveness and tolerability of off-label use of ketamine when administered via the transmucosal route.

\section{Methods}

This retrospective chart review was carried out at Chestnut Ridge Center (Morgantown, WV, USA), a comprehensive psychiatric treatment facility, and comprised records of patients with a diagnosis of treatment-resistant MDD who received clinical services as part of the day hospital program under the care of Dr Scott Pollard, between January 2011 and September 2013. The diagnosis of MDD was based on Diagnostic and Statistical Manual of Mental Disorders, Fourth Edition, Text Revision (DSM-IV-TR) criteria, ${ }^{31}$ and treatment resistance was defined as "failure to respond to two or more trials of antidepressant monotherapy or failure to respond to four or more trials of different antidepressant therapies", including augmentation, combination therapy, and electroconvulsive therapy. ${ }^{32}$ Trials with antidepressant monotherapy were each at least 6 weeks in duration. Augmentation therapies included the addition of an antipsychotic (eg, aripiprazole), lithium, a stimulant (eg, methylphenidate), another class of antidepressant (eg, mirtazapine or bupropion), or L-methylfolate. Typically, patients who were recommended to the day hospital program, which is synonymous with partial hospitalization, were either recently discharged from the inpatient unit or were failing outpatient care. Most participants were long-term patients with significantly persistent mental illness or patients who function in the community, but were at risk for inpatient admission or needed help through a turbulent period. Services provided at the day hospital included medical evaluation and education by an attending psychiatrist and medical staff in the morning, followed by group therapy sessions to help increase the patients' capacity to manage the symptoms of their illness and improve their quality of life. Of the patients with MDD who were seen in the day hospital setting during this period, those who were initiated on the transmucosal ketamine under off-label usage conditions along with treatment-as-usual for MDD were identified through the clinical notes in 18 files. Data were extracted from the medical charts of these 18 patients for demographic and illness variables, concurrent psychotropic medication use, dosing of ketamine, treatment response, and emergent side effects. Patients were classified as "responders" or "nonresponders" on the basis of the clinician's notes in the medical charts and/ or drug refill history pulled from the West Virginia Board of Pharmacy Controlled Substance Monitoring Program (WVBOP CSMP) database. For the drug refill history, we classified a patient as a responder if he/she filled the ketamine prescription more than once.

The data from all of the patients in this report have been de-identified. None of the patients were contacted to obtain additional clinical or biological data for the purposes of this manuscript. The Institutional Review Board of West Virginia University (Morgantown, WV, USA) approved the study.

\section{Results}

During the study period, 18 patients who were diagnosed with treatment-resistant MDD received transmucosal ketamine; one patient was excluded from the study due to significant changes in medication regimen after initiation of ketamine treatment. The demographic, clinical, and treatment variables of each subject collected from the chart review are detailed in Table 1. The mean age of the patients was 48 years (range 24-66), and 88\% were females. Of the 17 subjects included in the study, three had a prior history of substance abuse, though none had active substance abuse disorder at the time ketamine was initiated. Patients were generally administered $0.5 \mathrm{mg} / \mathrm{kg}$ to $1 \mathrm{mg} / \mathrm{kg}$ of ketamine from a $50 \mathrm{mg} / \mathrm{mL}$ vial of ketamine. In an effort to reduce side effects, liquid ketamine was placed on the tongues of the patients and they were instructed to hold it in their mouths for as long as possible. Thus, in contrast to standard oral dosing, where the drug is quickly swallowed, the administration route used in our patients may best be described as transmucosal. Moreover, dosing frequency started at every 14 days (based on the iv ketamine infusion clinical reports $)^{4,9,10}$ and was reduced to every 10 or 7 days when it became clear that the patient had loss of benefit prior to the 14 days.

Out of the 17 subjects who were treated with transmucosal ketamine, 13 (76\%) were classified as responders and four (24\%) as nonresponders. The onset of response was generally noted within 24 hours of taking ketamine. If patients did not respond within 24 hours, they typically received no benefit from taking ketamine. Among the responders, the frequency of dosing was based on the duration of the antidepressant effect, with seven subjects dosed once every 2 weeks, three once every 10 days, and one once every week. 


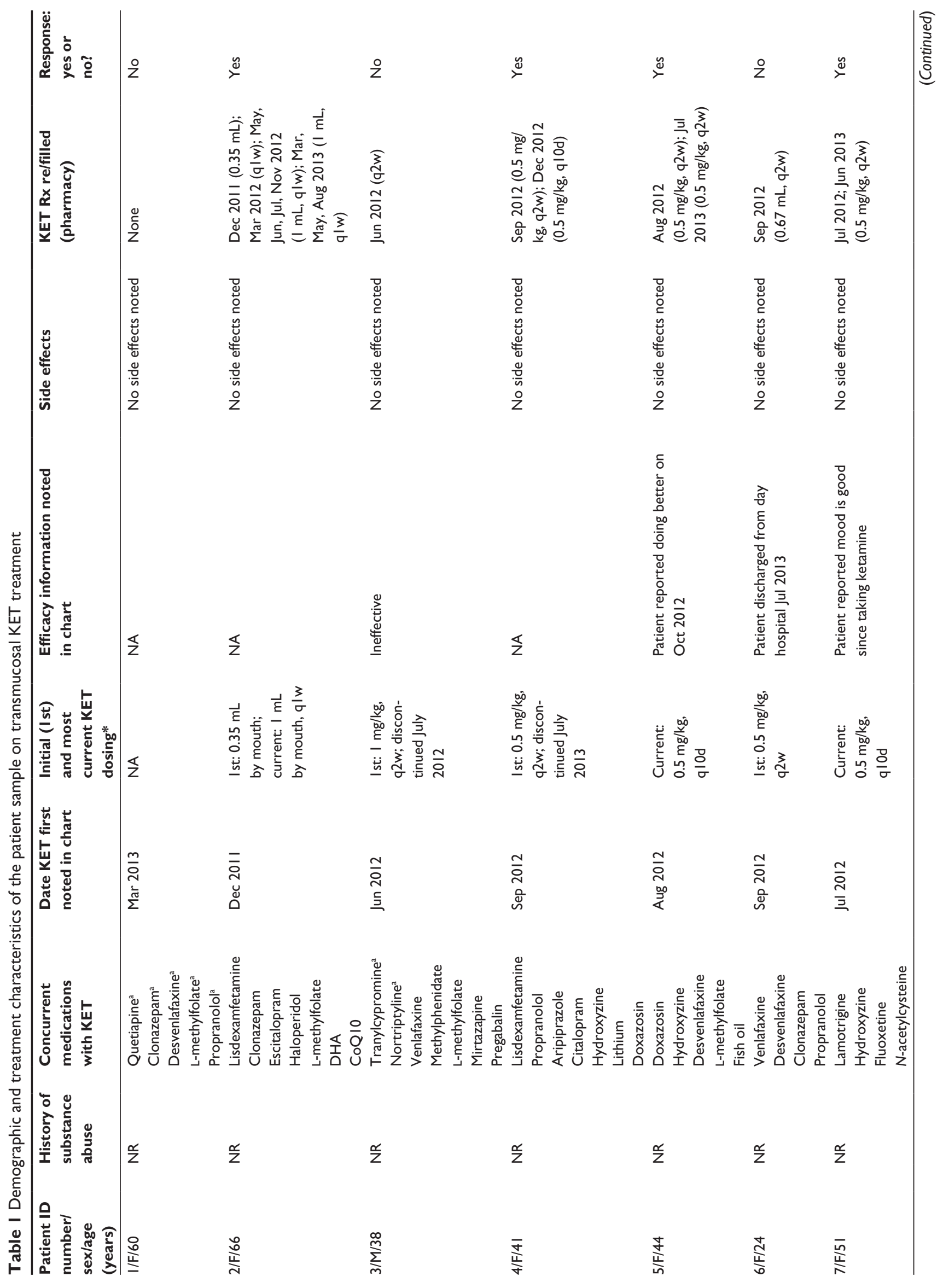




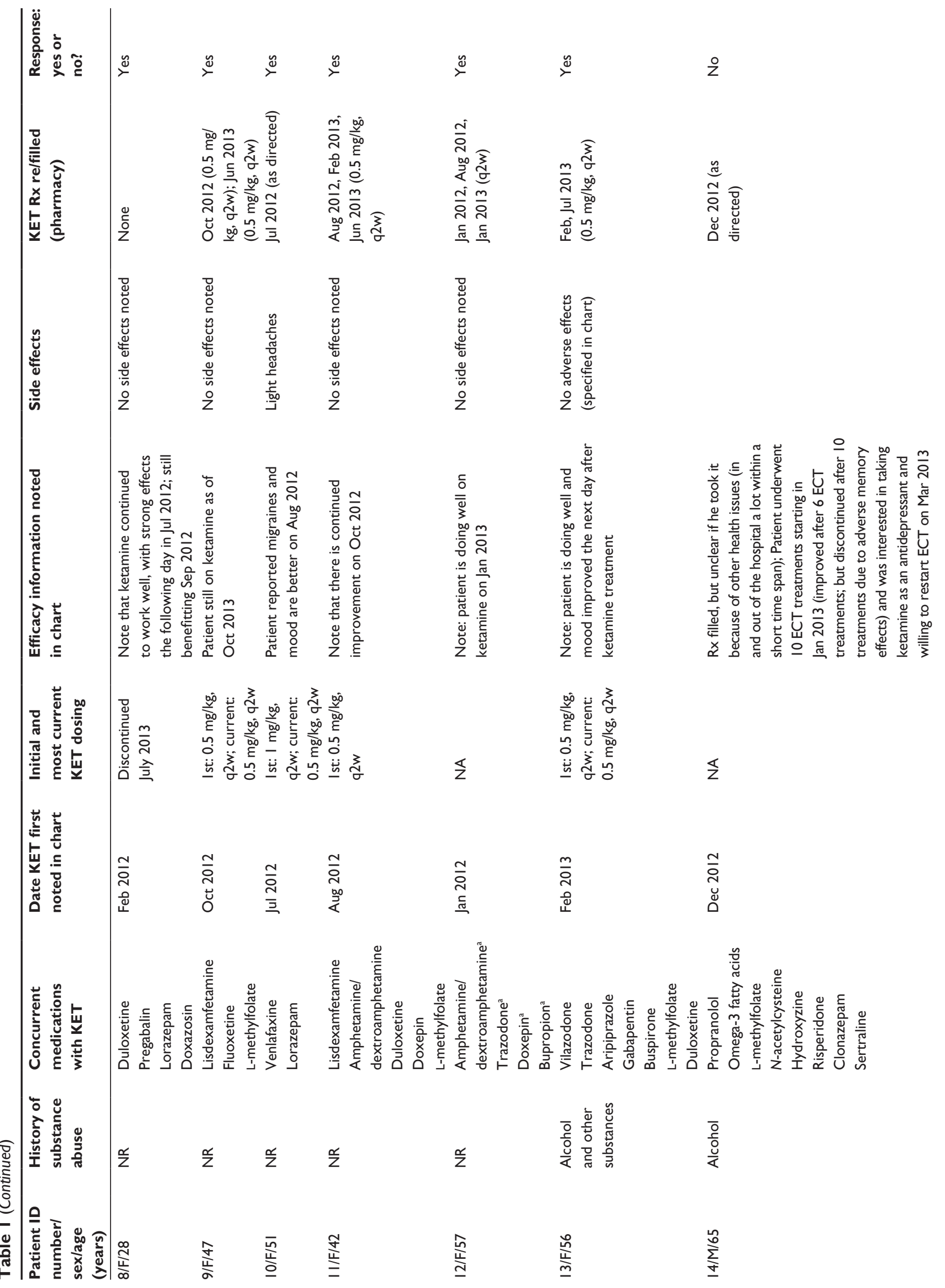


$\stackrel{y}{x}$

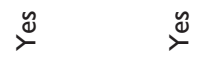

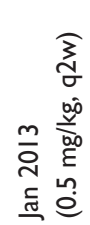

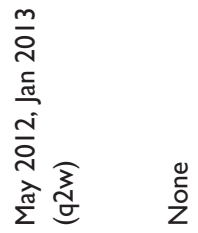

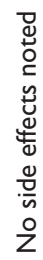

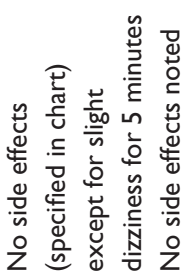

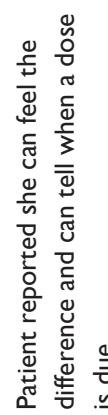

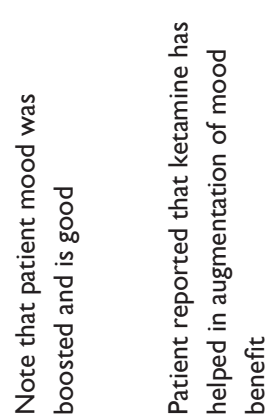

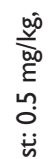

㟧 岂

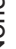

政

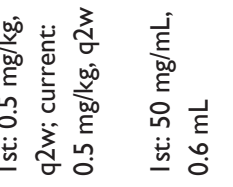
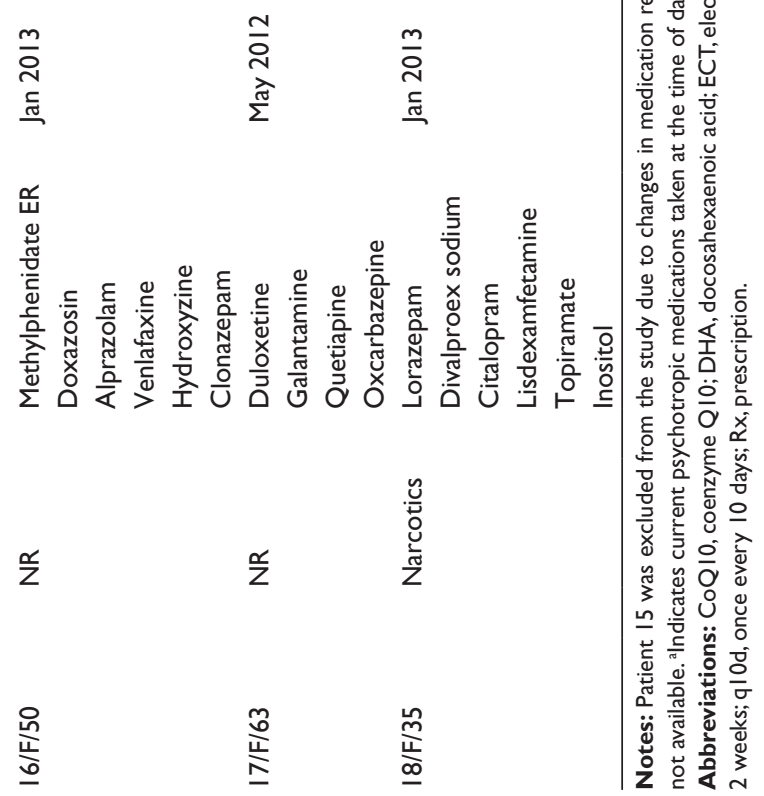

Table 2 Concurrent medications with ketamine

\begin{tabular}{ll}
\hline Medication & $\begin{array}{l}\text { Subjects taking } \\
\text { the drug (\%) }\end{array}$ \\
\hline SNRI & $59 \%$ \\
Stimulant & $47 \%$ \\
Folate replacement & $47 \%$ \\
Benzodiazepine & $47 \%$ \\
SSRI & $35 \%$ \\
Antipsychotic & $35 \%$ \\
HI-antihistamine & $29 \%$ \\
Beta blocker & $24 \%$ \\
Alpha blocker & $24 \%$ \\
TCA & $18 \%$ \\
Neuropathic pain treatment (pregabalin) & $12 \%$ \\
\hline
\end{tabular}

Abbreviations: SNRI, serotonin-norepinephrine reuptake inhibitor; SSRI, selective serotonin reuptake inhibitor;TCA, tricyclic antidepressant.

The remaining two responders (\#8 and \#18) did not have adequate information on maintenance dosing regimens. Of the 13 responders, two (\#2 and \#4) were based solely on the drug refill history (ie, the prescription was filled more than once but their charts had no note of efficacy). In addition, the clinical notes for two patients (\#8 and \#12) explicitly stated continued benefits with ketamine 6 months or more after the first ketamine treatment.

Of the four nonresponders ( $50 \%$ females), two had their prescriptions filled once: one had a note of inefficacy in the patient chart, and the other subsequently underwent and responded to ten electroconvulsive therapy treatments approximately 1 month after the prescription was filled. The other two nonresponders had no ketamine refill history and no reports of efficacy in their charts.

Other medications taken concurrently with ketamine included serotonin-norepinephrine reuptake inhibitors $(\mathrm{n}=10)$, stimulants $(\mathrm{n}=8)$, folate replacement $(\mathrm{n}=8)$, benzodiazepines $(n=8)$, selective serotonin reuptake inhibitors $(n=6)$, antipsychotics $(\mathrm{n}=6)$, and others (Table 2). Potential drug interactions or adverse effects are summarized in Table 3. Overall, no serious adverse events were noted in any of the subjects initiated on transmucosal ketamine. The two mild

Table 3 Potential drug interactions/adverse effects with ketamine

\begin{tabular}{ll}
\hline Medications & Side effects \\
\hline Clonazepam, lorazepam, pregabalin, nortriptyline, & CNS depression \\
hydroxyzine, doxepin, trazodone & \\
Haloperidol, mirtazapine, tranylcypromine & Additive CNS effects \\
Propranolol, doxazosin & Hypotension \\
Lisdexamfetamine, amphetamine/ & Cardiac effects \\
dextroamphetamine & \\
\hline
\end{tabular}

Abbreviation: CNS, central nervous system. 
side effects reported were transient light headache $(n=1)$ and slight dizziness $(n=1)$.

\section{Discussion}

This is an exploratory study in a naturalistic setting of the potential effectiveness and tolerability of transmucosal ketamine in 17 patients with treatment-resistant MDD. The findings in this chart review support previous reports of effectiveness of low-dose ketamine in rapidly alleviating symptoms of MDD, with effects lasting up to 2 weeks. Importantly, in contrast to iv ketamine, the administration of ketamine using the transmucosal route is better tolerated and has minimal psychiatric side effects. All patients were in a partial hospitalization program, wherein they were seen frequently and had adequate nursing support for administration/ education and observation with respect to ketamine. There were no adverse effects that would cause clinical concern for attempting to address depressive symptoms quickly in an atrisk, treatment-resistant population who otherwise are often being referred to high levels of care such as acute inpatient hospitalization.

A similar exploratory study has been conducted using low-dose sublingual ketamine in refractory unipolar and bipolar depression, in which patients were instructed to hold approximately $1 \mathrm{~mL}$ liquid ketamine in their mouths for 5 minutes and then swallow it. ${ }^{23}$ In that report, ketamine also produced rapid and relatively sustained antidepressant effects with only mild and transient light-headedness as a common side effect (no euphoria, psychotic or dissociative symptoms). ${ }^{23}$ Moreover, like the exploratory study using sublingual ketamine, the nature of our study provided an opportunity for reviewing treatment response in a "dirty" population that may be more representative of the treatmentresistant psychiatric patient pool, which is not possible with randomized controlled trials. Oftentimes, as in our chart review, the patients have multiple medical and psychiatric comorbidities, including but not limited to prior substance use disorders, chronic pain, attention deficit hyperactivity disorder, borderline personality disorder, and anxiety disorders like posttraumatic stress disorder. With that in mind, it is reassuring that the addition of low-dose ketamine had no serious adverse effects, including no drug-drug interactions or recurrence of substance misuse/abuse. Moreover, though side effects were not systematically monitored, it is important to note that these patients were a part of the day hospital program at the psychiatric center, participating in group therapy sessions often within 1 hour of taking transmucosal ketamine and having adequate medical support during their stay. None of the patients in our study discontinued using ketamine because of adverse events, with only mild, transient side effects noted (headache, dizziness).

This study has many limitations which are inherent to using a retrospective design. These include the lack of randomization and consistent baseline clinical data. Moreover, data for each variable were not available in every chart. As this was not a controlled study and our patient population had taken a number of medications which may affect the antidepressant effects and pharmacokinetics of ketamine, we were also unable to determine whether the positive effects of treatment were due to ketamine alone or a combination of ketamine and other therapies. In addition, no standardized clinical measures were used to evaluate depressive symptoms and adverse effects, including the monitoring of vital signs. Tachycardia and increased blood pressure in particular have been commonly observed following low-dose ketamine injections ${ }^{14}$ and should be systematically examined in future studies with transmucosal ketamine. The reliance on the drug refill history of a patient as an indicator of therapeutic efficacy introduces additional concerns that go beyond uncertainties regarding patient compliance and medication adherence. With the drug refill history omitted, however, ten of the 17 patients (ie, 59\%) would have been classified as "responders" from clinical notes of efficacy in the charts, which remains a sizeable proportion of the treatment-refractory population. Nevertheless, due to these limitations, a prospective, pilot study is strongly warranted to validate the efficacy of the transmucosal route of ketamine as a viable option for eliciting fast-acting and sustained antidepressant effects, with a side effect profile suitable for use in outpatients. Whether ketamine remains as effective if patients were withdrawn from their routine antidepressants is also of great interest.

\section{Conclusion}

This retrospective chart review describes the use of transmucosal ketamine for treatment-resistant depression and suggests that it may be a safe, tolerable, and effective antidepressant in some depressed patients.

\section{Acknowledgments}

The abstract of this paper was accepted for presentation at the 115th Annual Meeting of the American Association of Colleges of Pharmacy as a poster with interim findings. The poster's abstract was published in the American Journal of Pharmaceutical Education (2014;78(5):111; http://www. ncbi.nlm.nih.gov/pmc/articles/PMC4064488/). The actual paper has never been previously published. 


\section{Disclosure}

Several of the authors (SEP, PJM, RRM) are co-inventors on a US utility patent application (serial number 14/644,608), "Ketamine or dextromethorphan formulations and methods of use". The authors report no other conflicts of interest in this work.

\section{References}

1. Depression. Fact sheet No 369 [webpage on the Internet]. Geneva: World Health Organization; 2012. Available from: http://www.who. int/mediacentre/factsheets/fs369/en/. Accessed January 14, 2014.

2. Frazer A, Benmansour S. Delayed pharmacological effects of antidepressants. Mol Psychiatry. 2002;7 Suppl 1:S23-S28.

3. Al-Harbi KS. Treatment-resistant depression: therapeutic trends, challenges, and future directions. Patient Prefer Adherence. 2012;6:369-388.

4. Berman RM, Cappiello A, Anand A, et al. Antidepressant effects of ketamine in depressed patients. Biol Psychiatry. 2000;47(4):351-354.

5. DiazGranados N, Ibrahim LA, Brutsche NE, et al. Rapid resolution of suicidal ideation after a single infusion of an N-methyl-D-aspartate antagonist in patients with treatment-resistant major depressive disorder. J Clin Psychiatry. 2010;71(12):1605-1611.

6. Murrough JW, Iosifescu DV, Chang LC, et al. Antidepressant efficacy of ketamine in treatment-resistant major depression: a two-site randomized controlled trial. Am J Psychiatry. 2013;170(10):1134-1142.

7. Sos P, Klirova M, Novak T, Kohutova B, Horacek J, Palenicek T. Relationship of ketamine's antidepressant and psychotomimetic effects in unipolar depression. Neuro Endocrinol Lett. 2013;34(4):287-293.

8. Valentine GW, Mason GF, Gomez R, et al. The antidepressant effect of ketamine is not associated with changes in occipital amino acid neurotransmitter content as measured by [(1)H]-MRS. Psychiatry Res. 2011; 191(2):122-127.

9. Zarate CA Jr, Singh JB, Carlson PJ, et al. A randomized trial of an $\mathrm{N}$-methyl-D-aspartate antagonist in treatment-resistant major depression. Arch Gen Psychiatry. 2006;63(8):856-864.

10. Zarate CA Jr, Brutsche NE, Ibrahim L, et al. Replication of ketamine's antidepressant efficacy in bipolar depression: a randomized controlled add-on trial. Biol Psychiatry. 2012;71(11):939-946.

11. Lally N, Nugent AC, Luckenbaugh DA, Ameli R, Rosier JP, Zarate CA. Anti-anhedonic effect of ketamine and its neural correlates in treatmentresistant bipolar depression. Transl Psychiatry. 2014;4:e469.

12. Murrough JW, Perez AM, Pillemer S, et al. Rapid and longer-term antidepressant effects of repeated ketamine infusions in treatmentresistant major depression. Biol Psychiatry. 2013;74(4):250-256.

13. aan het Rot M, Collins KA, Murrough JW, et al. Safety and efficacy of repeated-dose intravenous ketamine for treatment-resistant depression. Biol Psychiatry. 2010;67(2):139-145.

14. Fond G, Loundou A, Rabu C, et al. Ketamine administration in depressive disorders: a systematic review and meta-analysis. Psychopharmacology (Berl). 2014;231(18):3663-3676.

15. McGirr A, Berlim MT, Bond DJ, Fleck MP, Yatham LN, Lam RW. A systematic review and meta-analysis of randomized, double-blind, placebo-controlled trials of ketamine in the rapid treatment of major depressive episodes. Psychol Med. 2015;45(4):693-704.
16. Luckenbaugh DA, Niciu MJ, Ionescu DF, et al. Do the dissociative side effects of ketamine mediate its antidepressant effects? J Affect Disord. 2014;159:56-61.

17. Irwin SA, Iglewicz A, Nelesen RA, et al. Daily oral ketamine for the treatment of depression and anxiety in patients receiving hospice care: a 28-day open-label proof-of-concept trial. J Palliat Med. 2013;16(8):958-965.

18. Iglewicz A, Morrison K, Nelesen KA, et al. Ketamine for the treatment of depression in patients receiving hospice care: a retrospective medical record review of thirty-one cases. Psychosomatics. 2015;56(4):329-337.

19. Irwin SA, Iglewicz A. Oral ketamine for the rapid treatment of depression and anxiety in patients receiving hospice care. J Palliat Med. 2010;13(7):903-908.

20. Chilukuri H, Reddy MP, Pathapati RM, Manu AN, Jollu S, Shaik AB. Acute antidepressant effects of intramuscular versus intravenous ketamine. Indian J Psychol Med. 2014;36(1):71-76.

21. Cusin C, Hilton GQ, Nierenberg AA, Fava M. Long-term maintenance with intramuscular ketamine for treatment-resistant bipolar II depression. Am J Psychiatry. 2012;169(8):868-869.

22. Lapidus KA, Levitch CF, Perez AM, et al. A randomized controlled trial of intranasal ketamine in major depressive disorder. Biol Psychiatry. 2014;76(12):970-976.

23. Lara DR, Bisol LW, Munari LR. Antidepressant, mood stabilizing and procognitive effects of very low dose sublingual ketamine in refractory unipolar and bipolar depression. Int J Neuropsychopharmacol. 2013; 16(9):2111-2117.

24. Paslakis G, Gilles M, Meyer-Lindenberg A, Deuschle M. Oral administration of the NMDA receptor antagonist S-ketamine as add-on therapy of depression: a case series. Pharmacopsychiatry. 2010;43(1):33-35.

25. Glue P, Gulati A, Le Nedelec M, Duffull S. Dose- and exposureresponse to ketamine in depression. Biol Psychiatry. 2011;70(4):e9-e10; author reply e11-e12.

26. Zanicotti CG, Perez D, Glue P. Mood and pain responses to repeat dose intramuscular ketamine in a depressed patient with advanced cancer. $J$ Palliat Med. 2012;15(4):400-403.

27. McNulty JP, Hahn K. Compounded oral ketamine. Int J Pharm Compd. 2012;16(5):364-368.

28. DiBonaventura MD, Wagner JS, Girman CJ, et al. Multinational Internetbased survey of patient preference for newer oral or injectable type 2 diabetes medication. Patient Prefer Adherence. 2010;4:397-406.

29. Yawn BP, Colice GL, Hodder R. Practical aspects of inhaler use in the management of chronic obstructive pulmonary disease in the primary care setting. Int J Chron Obstruct Pulmon Dis. 2012;7:495-502.

30. Yanagihara Y, Ohtani M, Kariya S, et al. Plasma concentration profiles of ketamine and norketamine after administration of various ketamine preparations to healthy Japanese volunteers. Biopharm Drug Dispos. 2003;24(1):37-43.

31. American Psychiatric Association. Diagnosis and Statistical Manual of Mental Disorders, Fourth Edition, Text Revision. Washington: American Psychiatric Association; 2000.

32. Campbell RJ. Campbell's Psychiatric Dictionary. 9th ed. New York: Oxford University Press; 2009.
Neuropsychiatric Disease and Treatment

\section{Publish your work in this journal}

Neuropsychiatric Disease and Treatment is an international, peerreviewed journal of clinical therapeutics and pharmacology focusing on concise rapid reporting of clinical or pre-clinical studies on a range of neuropsychiatric and neurological disorders. This journal is indexed on PubMed Central, the 'PsycINFO' database and CAS,

\section{Dovepress}

and is the official journal of The International Neuropsychiatric Association (INA). The manuscript management system is completely online and includes a very quick and fair peer-review system, which is all easy to use. Visit http://www.dovepress.com/testimonials.php to read real quotes from published authors. 